\title{
La moral de la compasión y la genealogía necesaria
}

\author{
ENCARNACIÓN RUIZ CALLEJÓN
}

I. «INSOLENTE, BURLÓN, DESTRUCTOR»

'Da capo' es la afirmación suprema de la moral aristocrática, pero conviene recordar que es también el programa de vida de alguien que no gozaba de una existencia muy gratificante y que conocía a fondo la fuerza disuasoria del sufrimiento a la que se había referido Schopenhauer. Esto la hace doblemente valiosa. Pero aún así, quien suscriba una afirmación de este tipo y quien, como Nietzsche, la extrapole a toda la realidad, tendría que plantearse algunas restricciones. Nietzsche tendría que explicar, por ejemplo, si su afirmación significaba otra cosa que un peligroso coqueteo con el dolor, y si incluía cualquier sufrimiento. Pero, sobre todo, esa especie de endurecimiento cuya última prueba -que sólo libra el personaje Zaratustra- es la superación de la compasión. La negación de la voluntad y, en general, el balance pesimista de la existencia en Schopenhauer, podían ser más o menos cuestionables; no lo era, sin embargo, su extraordinaria sinceridad respecto al sufrimiento, y el intento en sí por explicar y justificar nuestra relación con el mismo.

Es cierto que al planteamiento nietzscheano pertenece también la invocación de la alegría, la jovialidad e incluso a la risa. Pero resulta muy difícil mantener tan siquiera buen talante en los peores momentos. Es discutible que después de ciertas experiencias y teniendo presente la suerte de otros, quede mucha fuerza para evitar el hastío. Si no existe siquiera la solidaridad de los demás, parece imposible evitar la amargura. No es extraño que se genere un hábito casi enfermizo: cierta conformidad de vivir en el sufrimiento que acabe por distorsionar la percepción y los límites de lo que debe soportarse. La moral aristocrática, que afirma la vida tal cual es, tan exigente con el individuo, que niega la compasión, que incluso anima a la superficialidad, podría ser posible como mera declaración de intenciones o como una opción autodestructiva. No se puede justificar cualquier sufrimiento, ni reprochar a 
nadie no haber resistido lo suficiente, y no es coherente rechazar la compasión dentro de un discurso de carácter moral. Parece que rechazaríamos un afecto que funda una comunidad desinteresada entre los hombres. Corremos el riesgo de confundir buenos deseos, como el de salir adelante o el de autosuperarse, con algo muy diferente. A esto último se refiere Zaratustra como el gran peligro que amenaza al noble, a quien quiere crear algo nuevo, una nueva actitud. Tiene que ver, en cierto modo, con el cinismo: que se vuelva «insolente, burlón, destructor» ${ }^{1}$.

Si todo esto quiere decir la propuesta de Nietzsche, no puede tomarse en serio y resulta insultante para aquellos a los que les ha tocado la peor suerte. Si existe una posibilidad diferente a las anteriores, si la moral aristocrática pretende ser una opción seria a considerar, habrá que ver qué significa como síntoma de vida. En las páginas siguientes abordo parte de esta cuestión centrándome en la crítica de Nietzsche a Schopenhauer a propósito de la compasión.

\section{LA MORAL DE LA COMPASIÓN}

Schopenhauer afirma que el comportamiento moral es un hecho innegable y el verdadero objetivo de la filosofía: «El problema constante de la filosofía, desde Sócrates, viene siendo el de establecer una relación que enlace la fuerza que produce el fenómeno del mundo y que crea, por tanto, la naturaleza con la moralidad de los sentimientos; en otros términos: dar por base al orden físico un orden moral $»^{2}$. En Sobre el fundamento de la moral diferencia su propuesta de una exhortación a la virtud y rechaza las fundamentaciones teológicas, psicológicas o sociológicas; todo supuesto no demostrado y toda hipótesis metafísica o mística. Pretende un análisis objetivo y ajeno a toda moralina y a todo prejuicio. Sin duda, Kant merecía una consideración especial también aquí, en la filosofía práctica. Su aportación había supuesto un verdadero paso adelante. Pero, aún así, según Schopenhauer, parte de supuestos muy cuestionables y adolece de errores importantes. Concluye del análisis de la fundamentación kantiana que la ética no tiene nada que ver con imponer leyes. Los principios y reglas por sí solos no incitan nuestro comportamiento, ni nos paralizan. Tampoco pueden suscitar remordimiento alguno. Kant había intentado hacer de la ética una ciencia puramente a priori. Pero al rechazar que el fundamento esté en la conciencia, en «algo así como una disposición interna $»^{3}$, o en una relación objetiva con

${ }^{1}$ Así habló Zaratustra. Un libro para todos y para nadie, int., tr. y notas A. Sánchez Pascual, Alianza, Madrid, 1991, «Del árbol de la montaña», p. 74 (KSA IV 53).

${ }^{2}$ A. Schopenhauer, El mundo como voluntad y representación, tr. E. Ovejero y Maury, Aguilar, Madrid, Buenos Aires / México, 1960, libro IV, cap. 47, p. 213.

${ }^{3}$ A. Schopenhauer, Los dos problemas fundamentales de la ética, ed. P. López de Santa María, Siglo XXI, Madrid, 1993, «Sobre el fundamento de la moral», p. 157. 
el mundo, se convierte en algo absolutamente raro. Nos hemos quedado sin realidad. Una ley moral formada por conceptos y conexiones de juicios debe de contener la fuerza suficiente para frenar el 'ímpetu de las pasiones y el egoísmo. «Pero eso -afirma Schopenhauer- quisiéramos verlo» ${ }^{4}$. Por otra parte, la acción sólo tendría auténtico valor moral cuando se realiza por deber, pero esta exigencia conduce a situaciones tan paradójicas como la siguiente: «el valor del carácter no comienza hasta que alguien, sin simpatía en el corazón, frío e indiferente hacia los sufrimientos ajenos, y no nacido propiamente para la caridad [Menschenfreude], realiza, no obstante, buenas acciones sólo en razón del penoso deber $\rangle^{5}$. No tendríamos ninguna inclinación natural para ayudar a otro. Una concepción así de la ética, que nace de la coerción de la ley revela, a juicio de Schopenhauer, una moral de esclavos. Difícilmente se distinguiría un acto moral de una deducción lógica, de un comportamiento estratégico o del cumplimiento de cualquier otra ley civil. Pero hay algo más. Kant rechaza la compasión, un afecto distorsionador que resta autonomía al individuo.

La acción moral tiene que surgir de un afecto que se suscita ayudado por una comprensión intuitiva de las situaciones del entorno, de tal modo que se imponga inmediatamente a partir de la realidad de las cosas. Fundamentar la ética significa encontrar algún tipo de resorte, algún afecto en la naturaleza humana. De ahí que Schopenhauer anuncie un principio moral basado en la esencia de la naturaleza humana y, por ello, necesariamente efectivo ${ }^{6}$.

«Todo para mí y nada para los demás» ${ }^{7}$. Somos egoístas por naturaleza. Todas las acciones tienen que surgir o estar relacionadas con el impulso originario. La razón modela, diversifica e intensifica el egoísmo. El egoísmo es una fuerza contenida que estallaría de no ser contrarrestada por el único móvil moral y mantenida a raya por el temor que inoculan la sociedad y la religión. ¿Hasta dónde llega el egoísmo? Schopenhauer recurre a una hipérbole, aunque expresa su reserva de que se trate o no de una exageración: «algunos hombres estarían en disposición de matar a otro, simplemente para untarse las botas con su grasa ${ }^{8}$. Los acontecimientos del siglo siguiente, posiblemente lo hubiesen sacado de dudas. Pero el egoísmo no es la única potencia que el móvil moral tiene que combatir. A bajas dosis la malevolencia es casi incesante. Reanuda y continúa la guerra de todos contra todos, al menos en el pensamiento. Tiene un origen que el filósofo llama 'diabólico'. Hay un grado especial de la maldad que simboliza la bajeza moral. La crueldad y el sadismo ponen de manifiesto el lado más sombrío de la naturaleza humana.

\footnotetext{
${ }^{4}$ Ibid., p. 158.

${ }^{5}$ Ibid., p. 161.

${ }^{6}$ Cf. ibid., p. 145.

${ }^{7}$ Ibid., p. 222.

${ }^{8}$ Ibid., p. 224.
} 
No obstante, hay acciones de valor, genuinamente morales. Les acompaña una especial satisfacción con nosotros mismos y provocan el respeto y la aprobación de testigos imparciales. Son fenómenos que hay que referir a su fundamento, demostrando el resorte particular que nos motiva: «ese móvil, junto con la receptividad a él, será el fundamento último de la moralidad y su conocimiento, el fundamento de la moral» ${ }^{9}$. Algún resorte tiene que hacer frente a los móviles antimorales, algo tan inscrito en la naturaleza humana como la fuerza del egoísmo. Lo que mueve a la voluntad sólo puede ser el placer o el dolor. Si se trata del placer o el dolor propios la acción es egoísta, y por ello carece de valor moral. Pero es posible que el placer y el dolor del otro se conviertan en el motivo para mi voluntad, pero con una intensidad tal que renuncio a la satisfacción de los míos. No es el temor a la ley lo que suscitaría mi acción ni lo que reprocharía la conciencia. Lo determinante es el sufrimiento de otro ser que padece.

Para que esto ocurra tiene que darse un proceso muy profundo de identificación: «...supone necesariamente que yo com-padezca [mit-leide] directamente en $s u$ dolor como tal, que sienta $s u$ dolor como en otro caso sólo siento el mío y que, por lo tanto, quiera inmediatamente su placer como en otro caso sólo el mío» ${ }^{10}$. Se supera la diferencia que establece entre nosotros el egoísmo. Éste es el primer efecto de la compasión: «la participación totalmente inmediata e independiente de toda otra consideración, ante todo en el sufrimiento del otro y, a través de ello, en la obstaculización o supresión de ese sufrimiento, en la que en último término consiste toda satisfacción y todo bienestar y felicidad» ${ }^{11}$. La identificación que se requiere es extraña no sólo por la fuerza del egoísmo, sino porque «no me hallo en la piel del otro» ${ }^{12}$. El no-yo se convierte en cierta medida en yo, «pese a que su piel no esté conectada con mis nervios» ${ }^{13}$.Y si no puedo conectar con su sensibilidad, la otra vía de acceso es el conocimiento, concretamente la representación que tengo de él en mi cabeza. Sin embargo, Schopenhauer también afirma que a través de ese conocimiento ese sufrimiento se da como algo exterior. Precisamente por la intuición lo «con-siento, [mitempfinde], lo siento como mío, pero no en mí, sino en otro...» ${ }^{14}$. No puede tratarse de la simple representación. El proceso de conocimiento no es abstracto sino que consiste en una representación intuitiva, «...la mera captación del caso concreto a la que se reacciona inmediatamente sin ninguna mediación ulterior del pensamiento» ${ }^{15}$. No creemos que sufrimos su

\footnotetext{
${ }^{9}$ Ibid., p. 221.

${ }^{10}$ Ibid., pp. 232-233.

${ }^{11}$ Ibid., p. 233.

${ }^{12}$ Ibid.

${ }^{13}$ Ibid., p. 254.

${ }^{14}$ Ibid., p. 253.

${ }^{15}$ Ibid., p. 270.
} 
dolor en nuestra persona. «Es directamente en su persona, no en la nuestra, donde sentimos el sufrimiento para aflicción nuestra» ${ }^{16}$. La explicación de la compasión no es psicológica ${ }^{17}$. No es efecto de la fantasía. Sabemos quién es cada cual, pese a la angustia del momento. Es algo de lo que la razón no puede dar ninguna cuenta por vía inmediata y cuyos fundamentos no se pueden averiguar por vía de experiencia. «Es, en verdad, el gran misterio de la ética, su fenómeno originario y el mojón más allá del cual la especulación metafísica no puede atreverse a dar un paso» ${ }^{18}$.

Pero hay grados en la compasión. El primero, sólo es identificativo y origina la justicia libre. Identificamos al otro como un yo y nos abstenemos de causarle sufrimiento alguno. Este primer grado es represivo, se limita al control de los móviles antimorales. Neminem laede: no ofendas a nadie. El siguiente, es activo. Aquí se suprime o se alivia, en lo posible, el dolor de otro ser, originándose la caridad auténtica. «Omnes, quantum potes, iuva» ${ }^{19}$, expresa la compasión más perfecta. La justicia y la caridad son sustantivas cuando nacen de la compasión y sólo por ello tienen valor moral.

No es necesario que todo el proceso de la compasión se active desde el inicio ante cada nueva situación. Su efecto llegaría demasiado tarde. Basta con que hayamos tenido constancia de lo que significa la injusticia, el sufrimiento que conlleva y de lo que sentiríamos si estuviésemos en el lugar del que sufre. Se origina en el ánimo y se generaliza la represión de instintos inmorales. La reflexión la eleva a resolución. Y aunque los principios y el conocimiento abstracto no son el fundamento de la moral, sí son el depósito en el que se conserva el ánimo que nace de la moralidad. La consolidación y el seguimiento de los principios, a pesar de los motivos, lo llama Schopenhauer ‘autodominio'. Cuando los principios vacilan aún ayuda la representación del sufrimiento del otro. Al rememorar el sufrimiento se suscita la compasión como justicia, como 'represión' ${ }^{20}$.

La intersubjetividad se convierte así en medida de la subjetividad. Y ésta se polariza en un afecto que nos singulariza. Ante sucesos especialmente terribles exclamamos: «¿Cómo es posible hacer algo así? ¿Cuál es el sentido de esa frase? ¿Es quizá: cómo es posible temer tan poco los castigos de la vida futura? Difícilmente. ¿O: cómo es posible obrar según una máxima que es tan en absoluto inapropiada para convertirse en ley universal para todo ser racional? Seguro que no: ¿O: cómo es posible descuidar tanto la propia perfección y la ajena? Tampoco. El sentido de aquella pregunta es, con toda certeza, úni-

${ }^{16}$ Ibid., p. 236.

${ }^{17}$ Ibid.

${ }^{18}$ Ibid., p. 233.

${ }^{19}$ Ibid., p. 252.

${ }^{20}$ Ibid., pp. 238 y 263. 
camente éste: ¿Cómo es posible carecer por completo de compasión?» ${ }^{21}$. Ésta no depende de la cultura ni de la religión. Y favorecería también la unión con el resto de la naturaleza. Pero en el interior de cada hombre hay una mezcla irrepetible del móvil moral y los móviles antimorales. A ellos se reducen todas las acciones y refieren todos los motivos. En el curso de su vida sólo le afectarán aquellos motivos para los que tenga una mayor receptividad, «lo mismo que un cuerpo sólo reaccionará a ácidos y el otro sólo a cales: y como esto, tampoco aquello se puede cambiar ${ }^{22}$. Hay un abismo insalvable entre los hombres. «La diferencia de los caracteres es innata e indestructible» ${ }^{23}$. La virtud como disposición ética no se enseña. De lo contrario, la mitad más vieja de los hombres tendría que ser mejor respecto a la más joven. Pero nada de eso ha ocurrido. Ningún conocimiento ni ninguna ciencia pueden transformarnos: «Al malvado le es tan innata su maldad como a la serpiente sus colmillos y glándula venenosos; y tan poco como ella, puede él cambiarlo» ${ }^{24}$. Para una mejora real haría falta cambiar primero la receptividad para los motivos. Sería como pretender que un individuo fuese otro y «eso es imposible con mucha más certeza que el que se pudiera convertir el plomo en oro» ${ }^{25}$.

\section{EL IDEAL DE LA RENUNCIA}

Parecería entonces que la ética tiene en el sistema del filósofo la última palabra: conecta con la cosa en sí y mediante las consideraciones morales «se abren a nuestra contemplación las más íntimas honduras de nuestro ser». En las páginas dedicadas a la crítica de la filosofía kantiana afirma que el camino que él emprende se encuentra en un lugar intermedio entre la doctrina de la sabiduría total de la antigua dogmática y la desesperación de la crítica kantiana. Nietzsche presenta a Schopenhauer como un ateo que había lanzado una maldición contra el que arrebata al mundo su sentido moral. La posición atea de Schopenhauer ponía así el acento en otra función de la verdad. Hay una exigencia permanente de que la realidad última sea una respuesta que redima el sufrimiento porque desespera el sufrimiento que ha dejado de tener un para qué, como paraliza trabajar o luchar en vano. La crítica de Nietzsche se centrará en la fundamentación metafísica y atea de la ética y en el valor de la compasión. Lo primero hay que referirlo a la crítica que hace Nietzsche al ideal de verdad, un problema que atraviesa toda su obra, y que culmina en $L a$ genealogía de la moral. Una obra dedicada a los espíritus libres como Humano, demasiado humano refleja una voluntad que se ha impuesto la tarea de

${ }^{21}$ Ibid., p. 257.

${ }^{22}$ Ibid., p. 279.

${ }^{23}$ Ibid., p. 274.

${ }^{24}$ Ibid.

${ }^{25}$ Ibid., pp. 279-280. 
defender la vida contra el dolor y extirpar todos los razonamientos que nacen como hongos sobre el suelo del sufrimiento. Nietzsche desmonta una técnica muy común: aquellos razonamientos que debilitan y pretenden elevar experiencias personales a universales ampliándolas hasta condenar al mundo, y rechaza que la negación de la voluntad sea la única respuesta al sufrimiento. El dolor y el sufrimiento no se encuentran exactamente al mismo nivel que la enfermedad. Esta requiere un capítulo aparte. En Aurora ${ }^{26}$ se define la enfermedad en función de tres rasgos que suelen ir unidos: la vejez precoz, la fealdad y los juicios pesimistas. La vejez precoz como ocurre, por ejemplo, en la enfermedad histórica, en el cansancio de la vida y, en general, en la degeneración de los instintos vitales. La fealdad como símbolo de verdades afines a la silénica y como incapacidad para la belleza, aquella belleza que favorece la ilusión y que emana como reflejo del hombre que encuentra en sí mismo la medida de todas las cosas; los juicios pesimistas porque esconden una valoración negativa de la existencia. Y en 1875, refiriéndose a su enfermedad, escribe a un amigo que no es siquiera la muerte lo que más le asusta de la misma, «sino sólo la vida como enfermo, en la que se pierde la causa vitae». Fundamentalmente, hay dos grandes focos de la enfermedad: la inclinación natural interpretada como enfermedad y el conjunto de remedios que a lo largo de la historia se han utilizado para sanarnos. La gran enfermedad del hombre ha sido su lucha contra una supuesta enfermedad. En manos del espíritu 'sacerdotal' el ideal ascético adquiere una fisonomía enfermiza y una finalidad única centrada en la renuncia. «El signo distintivo en que se revela que el sacerdote (incluidos los sacerdotes enmascarados, los filósofos) se ha enseñoreado de todo, y no sólo de una determinada comunidad religiosa, el signo en que se revela que la moral de la décadence, la voluntad de final, se considera como moral en sí, es el valor incondicional que en todas partes se concede a lo no-egoísta, y la enemistad que en todas partes se dispensa a lo egoísta» ${ }^{27}$. A este contexto pertenece, según Nietzsche, el planteamiento de Schopenhauer. Por tanto, es una variante de la enfermedad. Y su terapia, la negación de la voluntad, parte del conjunto de esos remedios. La moral aristocrática representa, entre otras cosas, una alternativa al planteamiento de Schopenhauer: un ideal frente a otro ideal. Al espíritu libre le corresponde también arrancar la última máscara del ideal de verdad: la moral de la renuncia y la estética de la contemplación desinteresada. Ése es el gran paso hacia la salud.

En Aurora Nietzsche se refiere a la falta de 'historia' en Schopenhauer, es decir, de genealogía ${ }^{28}$. La genealogía discrimina qué ficciones sirven o no a la

${ }^{26}$ Cf. Aurora. Pensamientos sobre los prejuicios morales, ed. G. Cano, Biblioteca Nueva, Madrid, 2000, lib. IV, §409, p. 239 (KSA III 254).

${ }^{27}$ Ecce homo. Cómo se llega a ser lo que se es, ed. A. Sánchez Pascual, Alianza, Madrid, 1994, «Aurora. Pensamientos sobre la moral como prejuicio», §2, p. 89 (KSA VI 331).

${ }^{28}$ Cf. Aurora, lib. V, $\S 481$, p. 264 (KSA III 286). 
vida y qué tipo de vida las instrumentaliza. Esto supone 'rechazar mucho', pero también 'dejar vivir mucho'. Se desaprende mucho de lo aprendido. El problema es que el aprendizaje no es sólo cuestión de conocimiento. También se refiere a afectos y sentimientos. Tampoco se rechaza de cualquier forma. Hay un talante especial en el genealogista. Nietzsche le exige que se diferencie del moralista y que en sus palabras no haya desprecio. Por eso él mismo se aparta de los psicólogos del resentimiento y anuncia su intención de comportarse como un ángel frío que considerará el valor del conocimiento, pero también a los hombres, como objetos sometidos a un examen en el que se les debe hacer justicia.

Todos los filósofos han pretendido directamente una fundamentación, «la moral misma, sin embargo, era considerada como 'dada' ${ }^{29}$. Pero toda fundamentación no ha sido sino «una forma docta de la creencia candorosa en la moral dominante, un nuevo medio de expresión de ésta, y, por tanto, una realidad de hecho dentro de una moralidad determinada, más aún, en última instancia, una especie de negación de que fuera lícito concebir esa moralidad como problema». Schopenhauer también se limitó a erigir principios de sabiduría popular en verdades cuando lo que necesitamos es una 'tipología de la moral' y «recogida de material, formulación y clasificación conceptuales de un inmenso reino de delicados sentimientos y diferenciaciones de valor [...] y, acaso, ensayos de mostrar con claridad las configuraciones más frecuentes y que más se repiten de esa viviente cristalización ${ }^{30}$. Consideró al ser humano en un breve periodo de tiempo y lo dotó de una naturaleza estable. No cuestionó lo fundamental: la moral en sí misma, ni dos afectos como la compasión y el egoísmo. Un ejemplo es su actitud ante las objeciones del escéptico. Les opone directamente lo que considera un factum: existen hechos morales.

Negó que las facultades morales e intelectuales fuesen del mismo orden y dependiesen del cerebro. También aquí, a juicio de Nietzsche, falta historia y perspectiva psicológica. Nietzsche rechaza la existencia de facultades morales y de hechos morales. Sólo hay interpretaciones, y éstas responden a formas de vida. Pero ni siquiera las formas de vida son completamente originarias. Tampoco sabemos qué es la voluntad. Como en tantas ocasiones, sólo percibimos efectos. El cuerpo mismo es para nosotros un desconocido. Una de las tesis fundamentales la diferencia entre lo fenoménico y lo nouménico se basa en los errores del intelecto ${ }^{31}$. Schopenhauer agrupó los rasgos de la represen-

${ }^{29}$ Más allá del bien y del mal. Preludio de una filosofía del futuro, ed. A. Sánchez Pascual, Alianza, Madrid, 1982, sección V: «Para la historia natural de la moral», §186, p. 114 (KSA V 105-106).

${ }^{30}$ Ibid., p. 113 (KSA V 105).

${ }^{31}$ Humano, demasiado humano. Un libro para espíritus libres, 2 vols., ed. A. Brotons, Akal, Madrid, 2001, vol. I, «Fragmentos póstumos 1876-1878», p. 401 (KSA VIII 447). 
tación del mundo que dependían de la transmisión de errores intelectuales pero no señaló al intelecto como culpable, sino a la esencia de la cosa en sí como causa del carácter efectivo del mundo. Afirmó que la Voluntad tenía un significado último de carácter ético y que el grado más alto de sabiduría se identificaba con su reconocimiento. Pero todo lo necesario a la conservación de un tipo no tiene por qué existir. Y podría suceder que un individuo diferente ya no tuviese necesidad de ello, e incluso que con tales condiciones la vida le pareciese precisamente indigna de ser vivida ${ }^{32}$.

Los sentimientos morales son «pasiones transformadas por los juicios de valor $\rangle^{33}$. Y ni siquiera han sido los mismos en todas las épocas. Schopenhauer reivindicó la existencia de una conciencia moral en sentido estricto ${ }^{34}$. Pero la conciencia no fue originariamente moral. Al principio, lo importante es evitar lo desagradable. Luego, la sujeción se convierte en costumbre; con el tiempo, en libre obediencia; más tarde, casi en un instinto. Lo habitual y natural durante mucho tiempo acaba ligándose al placer y tomando el nombre de virtud. Así, poco a poco, surgió lo que es digno de veneración, lo más preciado. Schopenhauer no tuvo en cuenta el papel fundamental que desempeña el aprendizaje. La educación nunca es superficial, implica una transformación en la que nuevos valores se graban a fuego lento, hasta 'educar' la forma de sentir. Nietzsche se refiere a dos grandes procesos educativos: al proceso de humanización y al que pone en marcha el ideal judeo-cristiano. La obediencia ha sido hasta ahora la cosa mejor y más prolongadamente ensayada y cultivada.

La moral de la compasión no es una excepción. Quienes la defienden como instintiva olvidan la compleja economía de los afectos y un presupuesto fundamental: que toda moral es un constante dominio de sí mismo. Kant extrajo de la religión pesimista el mal radical y la creencia en que lo altruista era el rasgo distintivo de lo moral. Pero no querer lastimar a nadie, incluso ni a nosotros mismos, también puede ser índice de debilidad, de falta de decisión, incluso de indiferencia. Esta falta de psicología ha encumbrado el valor de lo no-egoísta y éste ha determinado el sistema de Schopenhauer ${ }^{35}$.

La historia de los sentimientos morales está basada en el sentimiento de responsabilidad. Pero la responsabilidad no es un dato originario. Primero se califican las acciones de justas porque sus consecuencias son útiles para una comunidad, pero no por sus motivos. Detrás hay disciplina, sacrificio y sufrimiento. Los actos ya no se refieren al bienestar momentáneo, sino a objetivos más duraderos determinados en función de las jerarquías de bienes de cada

${ }^{32}$ Cf. Aurora, lib. I, §90, p. 114 (KSA III 83-84).

${ }^{33}$ Nachgelassene Fragmente, Mai-Juni 1883, 9[39] (KSA X 357).

${ }^{34}$ Cf. A. Schopenhauer, Metafísica de las costumbres, ed. R. Rodríguez Aramayo, DebateCSIC, Madrid, 1993, cap. I: «Sobre la filosofía práctica en general», p. 3.

${ }^{35}$ Humano, demasiado humano, vol I, parte II, §37, pp. 66-67 (KSA II 59-61). 
comunidad. El individuo es colectivo. Y la jerarquía en sí no es moral, ni es estática. Es, una vez fijada, cuando recibe la sanción moral, lo que significa que 'moral' o 'inmoral' se identifica con 'convencional' y 'no convencional'. Luego se olvida el origen de esta designación y aparecen las acciones buenas o justas en sí mismas, tomándose así las consecuencias como causas. Más tarde, los actos considerados en sí mismos son moralmente indiferentes, pero no así los motivos, que son los que deciden sobre cada acto. Sin embargo, los motivos son complicados, difíciles de detectar. Después 'bueno' o 'malo' no son el motivo en sí, sino todo el ser de un hombre. Y éste se vuelve paulatinamente responsable de su influencia, luego de sus actos, de sus motivos y finalmente de su ser. Pero no es difícil comprobar que cada individuo es un producto de muchos factores, incluido el mundo de sus afectos, al que asiste más como espectador que como actor. Entonces el hombre ya no puede ser responsable de nada. «La historia de los sentimientos es la historia de un error, del error de la responsabilidad, el cual estriba en el error de la libertad del albedrío» ${ }^{36}$. Ante esta consecuencia, Schopenhauer aún podría replicar que sentimos pesar después de ciertas acciones, tenemos conciencia de una falta. Si no hubiese responsabilidad nos encontraríamos ante un pesar sin motivo. Aunque eso no probaría, según Schopenhauer, que el hombre tenga libertad en sus actos sino respecto a su ser. Sentiríamos pesar no frente al operari, sino frente al esse, frente a lo que somos cada uno de nosotros. De esta argumentación Nietzsche subraya lo absurdo de la consecuencia, que no consiste en que ante algunos actos reconozcamos que responden a rasgos inalterables de nuestra forma de ser, sino en lo siguiente: el hombre sería lo que él quisiese ser, pues «su voluntad es anterior a su existencia ${ }^{37}$. Y señala también un paso en falso, pues del pesar se concluye la justificación: «la admisibilidad racional de esta desazón» ${ }^{38}$. Más bien nos consideramos libres y sólo por eso sentimos pesar. Pero esto último es algo a lo que «uno puede deshabituarse» ${ }^{39}$. No todos lo experimentamos del mismo modo ni frente a los mismos actos. Es variable y depende de la historia de la evolución de la moral. Juicios, sentimientos, decisiones, afectos ocurren en nuestro interior de modo opaco para la conciencia. Sencillamente se nos imponen. «La plena irresponsabilidad del hombre respecto a sus actos y a su ser es la píldora amarga que tiene que tragar quien persigue el conocimiento cuando se ha habituado a ver en la responsabilidad y el deber el título de nobleza de su humanidad [...] no le cabe ya elogiar ni censurar, pues es absurdo elogiar y censurar la naturaleza y la necesidad $»^{40}$.

${ }^{36}$ Ibid., §39, p. 68 (KSA II 63).

${ }^{37}$ Ibid.

${ }^{38}$ Ibid. (KSA II, 64).

${ }^{39}$ Ibid.

${ }^{40}$ Ibid., §107, p. 94 (KSA II 103). 
¿Qué ocurre con el sentimiento de que se ha cometido una injusticia? ¿Qué sentido tiene la compensación? El enfado contra nosotros mismos es la principal razón del encono en la venganza, y también la ocasión para el refinamiento de ésta. Que todo es susceptible de ser contado y medido y que existe para cada cosa un equivalente es lo que ha llevado al pensamiento de que también hay un equivalente del daño, y a hablar de la compensación. Se olvida que hay otra cosa que no es un pago. La compensación no es más que una hipocresía y una manera de dorar la venganza. Es el sentimiento del vencido, el deseo de compensación, no el sentimiento de que se ha cometido una injusticia. La venganza es la conciencia de haber sido ofendido. Primero, de hecho; luego en nuestra conciencia, en nuestro poder. Exigimos defensa, después compensación y restablecimiento del sentimiento de poder, haciendo completa abstracción de la creencia en la culpabilidad del criminal. No es el sentimiento de que se ha cometido una injusticia, sino de que yo he sido vencido y debo exigir esta compensación por todos los medios. La injusticia sólo nace cuando se ha roto un tratado, se ha destruido la paz y se ha faltado a la fe prometida. El sentido de la pena no es intimidar, sino colocar a alguien en un puesto inferior en la organización social. Tan pronto como pensamos que el ataque a nuestro sentimiento de poder era lo que nos afligía, pasamos a reflexionar sobre cómo podremos aumentar el poder. Denota pobreza de espíritu obstinarse en devolver el daño que se ha recibido. Lo que aparece lesionado es el sentimiento de poder de la sociedad cuando alguien infringe la ley. En cambio, una hazaña heroica, una acción noble a favor de la sociedad podrá ser tenida en cuenta.

Todos los fenómenos históricos de la moralidad no se pueden simplificar, como pretende Schopenhauer, en uno de sus posibles resultados. La compasión y la renuncia son, ante todo, medios de control. La sociedad exige a todos una moral fundamental: bueno es «todo lo que de un modo u otro responde a este instinto de agrupación y a sus diversos instintos auxiliares $»^{41}$. Bajo los supuestos del bien común, el individuo desaparece en lo comunitario. Esta exigencia pretende algo imposible: el que el ego pueda obrar sin el ego, como si pudiéramos realizar alguna cosa sin un móvil personal, egoísta ${ }^{42}$. No podemos sentir por los demás. No sentimos más que por nosotros. Estimamos y amamos los sentimientos agradables que nos procuran. Las relaciones que consideramos altruistas consisten en una relación de intercambio de una cosa por otra que no tiene por qué ser moral. ¿No suele ocurrir, a veces que «el

${ }^{41}$ Aurora, lib. II, §132, pp. 144-145 (KSA III 124).

${ }^{42}$ «Nunca ha hecho hombre alguno nada únicamente en pro de los demás o sin algún móvil personal; más aún, ¿cómo podría hacer algo sin relación a él, es decir, sin motivación interna la cual debería, sin embargo, tener su fundamento en una necesidad personal)? ¿Cómo podría el ego obran sin el ego?» Humano, demasiado humano, vol I, parte III, §133, p. 109 (KSA II 127). 
hombre antepone algo de sí, un pensamiento, un anhelo, un producto, a algo distinto de sí, que por consiguiente, divide su ser y sacrifica una parte a las demás? ¿Es algo sencillamente diferente cuando un testarudo dice: "prefiero caer a cederle a este hombre el paso"? [...] En la moral, el hombre no se trata como individuum, sino como dividuum» ${ }^{43}$.

Hay una doble prehistoria del bien y del mal, diferencias en la percepción de lo injusto y en los niveles de dolor, que llevan a Nietzsche a afirmaciones de este tipo: el hombre cruel no es cruel "en la medida en que el maltratado cree; la representación del dolor no es lo mismo que su padecimiento [...] Causa y efecto están en todos estos casos rodeados por grupos de sentimientos y pensamientos enteramente diferentes; mientras que involuntariamente se presupone que el autor y la víctima piensan y sienten igual, y, conforme, a este presupuesto, se mide la culpa del uno por el dolor del otro» ${ }^{44}$. Aprendemos a sentir, a expresarnos y a comportarnos, también a comportarnos moralmente. Pero para esto último, hace falta, entre otras cosas, apreciar el modelo: haber aprendido a venerar. La compasión no es un afecto compacto. Hay morales más profundas que la que exige acciones altruistas ${ }^{45}$. La veneración a veces 'oscurece' y seca, como le ocurre al anticuario respecto al pasado. Lo envuelve todo en una especie de aura de santidad que exige fe y contemplación; ofrendas y sacrificios de todas clases. Para hacernos cargo del sufrimiento del otro también es necesario haber establecido e introyectado una base sobre la que entenderse e, incluso, un consenso sobre los límites del dolor. El sufrimiento ajeno se aprende, si bien nunca del todo ${ }^{46}$ y requiere, entre otras cosas, imaginación ${ }^{47}$. Respecto a la función de la imaginación en la compasión es clarificadora la apreciación de Aurelio Arteta: «Así como en el orden del saber conocer algo es representarlo y conocer el pensamiento de otro es poder reproducir su representación en la propia conciencia, en el orden de las emociones saber de la desgracia ajena es reproducir su sentimiento» ${ }^{48}$. En este caso, como en situaciones en las que se nos exige valorar o tomar decisiones, para ponerse en lugar de otro se necesita el recurso a la imaginación. Esto no resta

${ }^{43}$ Ibid., vol. I, parte II, §57, p. 76 (KSA II 76).

${ }^{44}$ Ibid., §81, p. 83 (KSA II 86).

45 «...toda tradición se hace cada vez más respetable cuanto más remoto se hace su origen, cuanto más se olvida éste; la veneración que se le tributa va acumulándose de generación en generación, la tradición acaba por sacralizarse y suscitar respeto; y así la moral de la piedad es en todo caso mucho más antigua que la que exige actos» ibid., §96, p. 88 (KSA II 93).

${ }^{46}$ Ibid., §101, p. 77 (KSA II 98).

47 «Inteligencia y moral. Hay que tener una buena memoria para poder cumplir promesas dadas. Hay que tener una gran fuerza de imaginación para poder compadecerse. Tan estrechamente ligada está la moral a la bondad del intelecto» Ibid., §59, p. 77 (KSA II 77).

${ }^{48}$ A. Arteta, La compasión. Apología de una virtud bajo sospecha, Paidós, Barcelona, 1996, p. 30. 
valor a la compasión ni a la sinceridad de un juicio. Pero nos indica la importancia de la individualidad del sujeto que compadece, su corporalidad y el significado de la experiencia personal, porque sólo proyectando las cuales es posible compadecer con el resto, pese a que Schopenhauer sólo subraye al objeto. Tampoco tiene en cuenta mecanismos previos como la empatía o el recurso a la analogía. En la crítica a Kant, Schopenhauer se refería a una investigación fisiológica del conocimiento, y a la importancia del cerebro incluso en nuestra percepción y valoración del dolor. Aquí está ausente, como está ausente una diferenciación de la compasión del mero instinto de supervivencia de la especie.

Pensamos, conscientemente o inconscientemente, en nosotros. Calificar de 'bueno' al compasivo y de especialmente 'malo' al individuo sin piedad, constituye una 'moda moral' ${ }^{2}$, y no precisamente la más duradera. Los afectos y sentimientos que se desencadenan son de muy variada índole. «Nos sentimos indignados ante cualquier dolor cuando es absurdo, cuando es 'inmerecido', (nuestra costumbre de reprochar y castigar obra aquí como el instinto herido: la imagen del que sufre es un ataque al fundamento de este instinto). Reaccionamos contra esta indignación con 'ayuda', etc. Acto seguido: nos estremecemos, sentimos la peligrosidad, la inseguridad, lo repentino de la desgracia [...]. Cuando sentimos que podemos ayudar crece nuestro sentimiento de po$\operatorname{der}[\ldots]$... ¡Amor, ternura, no son necesarias aquí! ${ }^{50}$. La desgracia que presenciamos quizá nos ofenda porque ponga de relieve nuestra impotencia o cobardía si no le ponemos remedio, genere una mala imagen ante los demás o ante nosotros mismos, o nos permita tomar conciencia de un peligro al que también podríamos estar expuestos. La incertidumbre y la fragilidad humana desencadenan en nosotros tristeza. Un acto compasivo puede encubrir una sutil defensa o también venganza. «Es algo confuso llamar com-pasión a la pasión que nos causa la visión de la miseria ajena...» ${ }^{51}$. El sufrimiento que experimentamos puede tener diferentes causas, pero no es el mismo que el que experimenta el que padece la desgracia ${ }^{52}$. Y la acción compasiva, que va acompañada de cierta alegría, tampoco es ingenua: presenciamos una situación contraria a la nuestra, seremos objeto de elogios y de reconocimiento, sentiremos la medida de nuestra fuerza, etc.

En otras culturas, como por ejemplo, la griega, manifestar compasión equivalía a un signo de desprecio. Cuando inspiramos compasión automáticamente hemos dejado de inspirar temor. La cantidad de poder que representamos dis-

${ }^{49}$ Aurora, lib. II, §133, p. 146 (KSA III 127).

${ }^{50}$ Nachgelassene Fragmente, Frühjahr-Sommer 1883, 7[9] (KSA X 240-241).

${ }^{51}$ Aurora, lib. I, §133, p. 145 (KSA III, 126).

${ }^{52}$ «Pero es precisamente esta pasión la que descargamos de nosotros cuando realizamos acciones de compasión» Ibid., p. 146 (KSA III 146). 
minuye, peor aún, queda roto el equilibrio con respecto a los demás, los iguales. Se ataca un sentimiento fundamental del hombre: el ansia de preponderancia. La visión y la conciencia del sufrimiento de otro que admiramos o amamos produce un tipo de igualdad que rebaja. La admiración o amor que experimentamos se transforma: «sólo entonces es cuando nos parece posible devolverle algo [...]. Este poder dar algo a cambio nos conmueve y nos causa gran placer ${ }^{53}$. Ese algo que se da a cambio es muy variado: palabras de consuelo, atenciones, miradas, servicios, etc. La donación extrema es vernos sufrir al contemplar su sufrimiento. Y hacemos que sufrimos, «pues ello nos proporciona, antes que nada, el placer del agradecimiento activo, algo, en definitiva, equivalente a una buena venganza» ${ }^{54}$. Esto permite concluir que «incluso en el mejor de los casos, el dolor tiene algo de humillante, y la compasión algo que eleva y nos hace superiores, lo cual separa eternamente ambos sentimientos» ${ }^{55}$. No sólo haciendo mal ejercemos nuestro poder, sino también haciendo bien. Cuando pretendemos sólo hacer sentir nuestro poder sobre otros, hacemos el mal. Es especialmente gratificante cuando precede una disminución de éste, es decir, en la venganza. Para ello el dolor es un medio mucho más penetrante que el placer, pues el dolor siempre indaga la causa, mientras que el placer se detiene en sí mismo y no mira hacia atrás. Haciendo bien aumentamos el poder de los beneficiarios y, como consecuencia, nuestro poder sobre ellos. El placer de hacer bien se ha desarrollado sobre la misma base. La generosidad, por ejemplo, es una venganza sublimada, y por ello, un placer mucho mayor ${ }^{56}$. Desde esa perspectiva, hacer bien o mal sería, según Nietzsche, una cuestión de preferencia: dependerá de la forma escogida de "condimentar" la propia vida. Preferimos el aumento de poder lento o el brusco; el seguro o el más peligroso. Eligen la compasión los que no tienen mucho orgullo ni perspectiva de grandes conquistas ${ }^{57}$.

Por otra parte, la compasión es muy parcial. Sólo podemos abarcar partes aisladas de la vida. Inferimos y deducimos al: 'prójimo' a partir de nosotros mismos, y esto según nuestra capacidad de observación. Le comunicamos los rasgos que reaccionan a nuestros instintos. No podemos conocerlo en sí mismo. Pero si pudiéramos, y acepta nuestro sacrificio, para un cristiano sería un egoísta que acepta ese 'vivir para ‘él'. Esto conduciría a la siguiente situación: «la moralidad suprema, para poder existir, debería por así decir forzar la existencia de la inmoralidad (a través de la cual se superaría por cierto a sí misma)» ${ }^{58}$.

${ }^{53}$ Ibid., lib. II, §138, p. 149 (KSA III 131).

${ }^{54}$ Ibid.

${ }^{55}$ Ibid.

${ }^{56}$ Nachgelassene Fragmente, Herbst 1883, 16[25] (KSA X 507).

${ }^{57}$ Cf. La ciencia jovial [La gaya scienza], lib. I, § 13, ed. G. Cano, Biblioteca Nueva, Madrid, 2001, pp. 104-106 (KSA III 384-386).

${ }^{58}$ Humano, demasiado humano, vol. I, parte III, §133, p. 110 (KSA II 127-128). 
Existe, además, una especie de cansancio de la compasión ${ }^{59}$ que puede ser incluso un mecanismo defensivo natural: exige un gran esfuerzo mantenerse mucho tiempo en este estado de ánimo. Casi 'sin transición' los espectadores del sufrimiento lo justifican, como algo que se deduce del carácter del sufriente, por tanto algo merecido que invalida todo acto del compasivo ${ }^{60}$.

La Rochefoucauld calificó la compasión como necesidad de los desdichados, producto de una especie de estupidez y de falta de inteligencia, que se aúnan a la perturbación espiritual que la desgracia conlleva. Observaba de cerca encubre' según Nietzsche algo más sutil: el arma secreta de los débiles. Toda su exhibición del infortunio, más que reclamar ayuda, persigue hacer mal a los espectadores. La compasión que estos expresan es un consuelo para los débiles, en cuanto reconocen tener allí un poder: el poder de hacer mal. También desde el lado del desdichado, la compasión es «una sed de goce de sí mismo, y ciertamente a costa del prójimo; muestra al hombre en toda la brutalidad de su querido yo más propio, pero no precisamente en su 'estupidez', como opina La Rochefoucauld ${ }^{61}$. A dosis pequeñas, controladas y sublimadas, la malignidad es un poderoso medio de excitación de la vida, pero la benevolencia no es muy diferente ${ }^{62}$. Hay una recepción peculiar de la compasión en el alma de los impotentes. Como todo hombre pasa aquí por hostil y explotador, como todo hombre es malo, las muestras de bondad se soportan con angustia como maldades, medios de «aturdimiento y engaño, en una palabra, como maldad refinada» ${ }^{63}$.

En La gaya ciencia Nietzsche califica a la ayuda que presta el compasivo como algo más que inoportuna. Carece de pudor. Son precisamente los que más nos conocen los que más rebajan nuestro valor y voluntad. Nada saben del proceso interior ${ }^{64}$. Banalizan el sufrimiento y adoptan una actitud cómoda, ocupados en deshacerse lo más pronto posible del dolor que agobia. La com-

\footnotetext{
${ }^{59}$ Sobre este tipo de 'cansancio' también ha hablado otros autores modernos refiriéndose a las relaciones entre estados o donantes privados y los receptores: «El cansancio de la compasión (...) puede dejar de ser un simple hartazgo y convertirse en una repugnancia activa hacia la incapacidad de estas sociedades receptoras de la ayuda para cuidar de sí mismas» M. Ignatieff, El honor del guerrero. Guerra étnica y conciencia moderna, tr. P. Linares, Taurus, Barcelona, 1999, p. 95.

${ }^{60}$ Humano, demasiado humano, vol. II, «El caminante y su sombra», §314, p. 213 (KSA II 692).

${ }^{61}$ Ibid.,vol. I, parte II, §50, p. 73 (KSA II 71).

${ }^{62}$ Ibid.

${ }^{63}$ Ibid., §45, p. 71 (KSA II 68).

${ }^{64}$ «Toda la economía de mi alma y su balance efectuado por la "desdicha", la irrupción de nuevas fuentes y necesidades, la manera en la que cicatrizan las viejas heridas, el modo de rechazar pasados enteros [...] carece de interés para el amado compasivo: él quiere ayudar, sin pensar que existe una necesidad personal de la desdicha...» La ciencia jovial, lib. V, §338, p. 322 (KSA III 566).
} 
pasión inyecta la intención de prestar ayuda a toda costa sin atender al origen de la enfermedad, a su tipología. Por eso «el noble se exige a sí mismo no causar vergüenza: se exige a sí mismo tener pudor ante todo lo que sufre» ${ }^{65}$.

Tampoco la renuncia en sí misma es moral. La crueldad y la renuncia han servido para predisponer positivamente a los dioses, como prueba de la legitimidad o la sinceridad de un nuevo ideal o de una institución que quería imponerse. Si el nivel de moralidad en un individuo se juzga por esa capacidad de desprendimiento hasta el gran sacrificio, el cual convertido en hábito se denomina santidad, es en la pasión donde sería, paradójicamente, más moral. Bajo la influencia de una emoción violenta, el hombre quiere lo grande, lo monstruoso, que puede encontrarlo en la venganza más terrible o en el sacrificio de sí mismo, lo cual comprueba que le dispensa igual o más satisfacción que el sacrificio ajeno ${ }^{66}$. Los actos considerados propiamente morales son de este tipo. En ellos el beneficiario es el que ofrece al individuo en tensión la ocasión de liberar su estado anímico. En una representación, por ejemplo, el individuo quiere emociones sin tener que prestar ningún socorro. El mismo proceso, pero de forma extrema, ocurre en la crueldad. Ni siquiera el santo o el asceta constituyen una excepción, al menos no por la bondad de su renuncia. Conocemos las descripciones que hace Nietzsche de la psicología del santo. Éste y, en general, el asceta también buscan hacerse la vida más 'ligera'67. 'Ligera' significa aquí soportable y justificada. Para ello hay que buscar los propios remedios. Se puede elegir la sumisión completa a una voluntad extraña, a una ley, a un ritual. Ceder la propia voluntad, someterse, es un mecanismo para hacerse dueño de sí, pues se evita la decisión, el conflicto y la propia experiencia de las cosas. Sin embargo, en la extraordinaria valoración que nos merece la figura del santo se confunden la renuncia y el abandono de la propia personalidad con el heroísmo de la moralidad.

Nietzsche rechaza el valor, no adaptativo, sino evolutivo de la compasión: «este instinto depresivo y contagioso pues implica otro obstaculiza aquellos instintos que tienden a la conservación y a la elevación de valor de la vida: tanto como multiplicador de la miseria cuanto como conservador de todo lo miserable...» ${ }^{68}$. No se alía a las fuerzas que estimulan y aumentan la vida. No es siquiera una fuerza tonificante. Sólo parece poder hacerse el bien en medio del sufrimiento: "“sólo la propia desgracia hace a uno prudente, sólo la des-

${ }^{65}$ Así habló Zaratustra, «De los compasivos», p. 135 (KSA IV 113).

${ }^{66}$ «Que en la abnegación y no sólo en la venganza hay algo grande debió inculcársele a la humanidad mediante una larga habituación, una deidad que se sacrifica a sí misma fue el símbolo más fuerte y más eficaz de esta clase de grandeza» Humano, demasiado humano, vol. I, parte III, §138, p. 113 (KSA II 132).

${ }^{67}$ Ibid., §139, p. 113 (KSA II 133).

${ }^{68}$ El Anticristo. Maldición sobre el cristianismo, ed. A. Sánchez Pascual, Alianza, Madrid, 1995, §7, p. 32 (KSA II 68-69). 
gracia ajena le hace bueno", así reza esa curiosa filosofía que deriva toda moralidad de la compasión y toda intelectualidad del aislamiento del hombre; con ello es inconscientemente la abogada de toda perniciosidad terrena. Pues a la compasión le es menester el sufrimiento, y al aislamiento el desprecio de los demás $»^{69}$. Es un tipo de enfermedad que vuelve hipocondríacos ${ }^{70}$ a los hombres. Es un parásito dañino de la salud moral e incluso de la vida. En el mundo griego se consideró un proceso enfermizo que a veces padece el individuo y que debía tratarse ${ }^{71}$. Sencillamente la compasión «obstaculiza en conjunto la ley de la evolución, que es la ley de la selección» ${ }^{72}$. La fuerza evolutiva está en el egoísmo.

\section{EL CULTIVO DE LO NECESARIO}

Según David E. Cartwright ${ }^{73}$, Schopenhauer y Nietzsche utilizan el mismo término (Mitleid) pero se refieren a emociones o afectos distintos. Schopenhauer nos presenta la compasión genuina. Mientras que Nietzsche, basándose en Kant aunque de modo más sofisticado, se ocupa de denunciar la falsa compasión y los afectos que esconde.

Sin embargo, habría que plantearse qué compasión defiende Schopenhauer. El primer obstáculo es que depende del carácter y frente a éste se puede hacer bien poco. En cada situación siempre podríamos haber hecho otra cosa, pero sólo si hubiéramos sido otros. Lo aterrador de esta doctrina y la tragedia de nuestra situación es que seamos culpables de ser lo que somos. Y entonces de nada sirven el conocimiento, la educación, el perdón o el arrepentimiento. Y aún sintiendo compasión, ésta sería, en realidad, una manifestación más de la Voluntad. La ética acabaría por disolverse en un proyecto en el que la ascética y la mística tienen la última palabra. Sin embargo, hay en el planteamiento de Schopenhauer un fondo de verdad que nos desconcierta: ante algunos de nuestros comportamientos, alguna vez hemos sentido que nada podría haber discurrido de otro modo.

Nietzsche se ocupa, sobre todo, de la falsa compasión, pero hay referencias críticas a la supuestamente verdadera. Critica al compasivo porque carece de pudor y a una moral basada en la compasión porque sólo sería posible si existe

${ }^{69}$ Humano, demasiado humano, vol. II, «El caminante y su sombra», §62, p. 142 (KSA II 580-581).

${ }^{70}$ Ibid., vol. I, parte II, §47, p. 71 (KSA II 68-69).

${ }^{71}$ «Aristóteles, como se sabe, veía en la compasión un estado enfermizo y peligroso, al que haría bien en tratar de vez en cuando con un purgativo: él concibió la tragedia como purgativo» El Anticristo, §7, p. 32 (KSA VI 174).

${ }^{72}$ Ibid., p. 31 (KSA VI 173).

${ }^{73}$ Cf. D.E. Cartwright, «Kant, Schopenhauer, and Nietzsche on the morality of pity», In Journal of the history of ideas, 45, 1984, 83-98. 
el sufrimiento. Pero no sólo es el dolor el que estimula el sentimiento de comunidad entre los hombres. De cualquier modo, habría que matizar si Nietzsche renuncia completamente a la compasión que expone Schopenhauer, con sus dos grados. El que no la desarrolle en sus escritos, como Schopenhauer no trate la falsa, no implica un rechazo. Zaratustra se muestra compasivo con el volatinero moribundo. Y hay un sentimiento similar en el hombre trágico: «se vuelve con mirada quieta hacia la imagen total del mundo e intenta aprehender de ella, con un sentimiento simpático de amor, el sufrimiento eterno como sufrimiento propio» ${ }^{74}$. Es la doble visión, el ojo vidriado por el dolor del hombre dionisiaco. La piedad es un afecto positivo que se experimenta ante lo sagrado. Lo sagrado inspira terror y respeto. También se experimenta ante lo insondable de la existencia, ante la grandeza de la naturaleza humana o a cierta profundidad en el conocimiento. El hombre y la vida suscitan, en ese sentido, piedad. Tal y como pone de manifiesto Peter Berkowitz, el término Ehrfurcht «es una palabra de fuertes connotaciones religiosas que significa una combinación de respeto y temor o miedo. En efecto, Nietzsche transfiere la pasión que el conocimiento de Dios despierta en el alma de un piadoso cristiano a la pasión que el conocimiento de sí misma despierta en el alma noble» ${ }^{75}$. El hombre noble siente este tipo de respeto ante sí mismo.

En una carta de diciembre de 1875, refiriéndose a uno de los rasgos de la personalidad de su amigo Gersdorff, anuncia un afecto mucho más valioso: «tienes, déjame decírtelo, la magnífica capacidad de compartir las alegrías ajenas, capacidad para mí más rara y noble que la de compadecer» ${ }^{76}$. Y en los fragmentos póstumos de la época de Humano, demasiado humano se refiere a una ética superior: «Los que saben congratularse con nosotros están por encima y más cerca de nosotros que los que nos compadecen. La congratulación hace al 'amigo' (el que se congratula), la compasión hace al compañero de penas. Una ética de la compasión precisa del complemento de la ética aún superior de la amistad» ${ }^{77}$. El espíritu aristocrático es compasivo. Existe reciprocidad y ayuda entre los semejantes. Sólo entre los amigos existe un tipo de igualdad que no rebaja ni somete: «...sólo a los necesitados que comprendas plenamente, porque comparten contigo un sufrimiento y una esperanza -tus amigos: y sólo en la medida que te ayudas a ti mismo- iquiero hacer de ellos hombres más valerosos, más resistentes, más sencillos, más joviales! Quiero

${ }^{74}$ El nacimiento de la tragedia o Grecia y el pesimismo, ed. A. Sánchez Pascual, Alianza, Madrid, 1991, cap. 18, p. 148 (KSA I 118).

${ }^{75}$ P. Berkowitz, Nietzsche. La ética de un inmoralista, ed. M. Cóndor, Cátedra, Madrid, 2000, «La ética del conocimiento: Más allá del bien y del mal», p. 311.

${ }^{76}$ Epistolario, tr. L. López-Ballesteros y de Torres, rev. J. Muñoz, Biblioteca Nueva, Madrid, 1999, 138.

${ }^{77}$ Humano, demasiado humano, vol. I, «Fragmentos póstumos 1876-1878)», p. 309 (KSA VIII 333). 
enseñarles lo que hoy muy pocos entienden, y menos que nadie los ya citados predicadores de la compasión -ila alegría compartida! ${ }^{78}$.

En todos estos casos no se descarta del todo la compasión. La cuestión es si esto es suficiente. Schopenhauer carece de un estudio más profundo de lo humano y su concepto de compasión es criticable, pero le corresponde el mérito de subrayar la importancia de lo humanizante. En Nietzsche hay un ideal más perfecto que el de Schopenhauer, pero también mucho más difícil: la moral de la amistad se extiende sólo a los más cercanos. Nietzsche dice del hombre aristocrático que también profesa un credo y que necesita de ilusiones y convenciones. Las hay que salvaguardan la dignidad humana. Esa es una de las razones por las que cultiva la voluntad de no saber y una ciencia ligera. Nietzsche, además, exige a toda filosofía que supere una prueba definitiva ${ }^{79}$ : si puede vivirse con ella y de qué modo. Puede que los problemas de nuestra época nos exijan aceptar la genealogía sólo como informativa y haya beneficios en los falsos afectos. En ese sentido, la posición de Voltaire a propósito de la virtud, podría representar una actitud más acorde con las necesidades de nuestro tiempo: «...Algunos teólogos dicen que el divino emperador Antonio no era virtuoso [...] que refería a sí mismo el bien que hacía al género humano; que fue toda su vida justo, laborioso, benéfico por vanidad, y que no hizo otra cosa que engañar a los hombres con sus virtudes. Entonces, exclamo: ¡Dios mío, dadnos con frecuencia bribones como éste! ${ }^{80}$.

${ }^{78}$ La ciencia jovial, lib. IV, §338, p. 324 (KSA III 568).

${ }^{79}$ Cf. Schopenhauer como educador, ed. Jacobo Muñoz, Biblioteca Nueva, Madrid, 2000, $\S 8$, p. 112 (KSA I 417).

${ }^{80}$ Voltaire, Diccionario filosófico, ed. A. Garzón del Camino, Compañía General de Ediciones, México, 1967, «Virtud», pp. 381-382. 